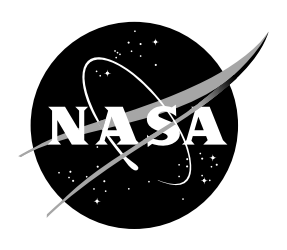

\title{
Radio Frequency Mass Gauging of Propellants
}

Gregory A. Zimmerli and Karl R. Vaden

Glenn Research Center, Cleveland, Ohio

Michael D. Herlacher

Analex Corporation, Brook Park, Ohio

David A. Buchanan and Neil T. Van Dresar

Glenn Research Center, Cleveland, Ohio 


\section{NASA STI Program . . . in Profile}

Since its founding, NASA has been dedicated to the advancement of aeronautics and space science. The NASA Scientific and Technical Information (STI) program plays a key part in helping NASA maintain this important role.

The NASA STI Program operates under the auspices of the Agency Chief Information Officer. It collects, organizes, provides for archiving, and disseminates NASA's STI. The NASA STI program provides access to the NASA Aeronautics and Space Database and its public interface, the NASA Technical Reports Server, thus providing one of the largest collections of aeronautical and space science STI in the world. Results are published in both non-NASA channels and by NASA in the NASA STI Report Series, which includes the following report types:

- TECHNICAL PUBLICATION. Reports of completed research or a major significant phase of research that present the results of NASA programs and include extensive data or theoretical analysis. Includes compilations of significant scientific and technical data and information deemed to be of continuing reference value. NASA counterpart of peer-reviewed formal professional papers but has less stringent limitations on manuscript length and extent of graphic presentations.

- TECHNICAL MEMORANDUM. Scientific and technical findings that are preliminary or of specialized interest, e.g., quick release reports, working papers, and bibliographies that contain minimal annotation. Does not contain extensive analysis.

- CONTRACTOR REPORT. Scientific and technical findings by NASA-sponsored contractors and grantees.
- CONFERENCE PUBLICATION. Collected papers from scientific and technical conferences, symposia, seminars, or other meetings sponsored or cosponsored by NASA.

- SPECIAL PUBLICATION. Scientific, technical, or historical information from NASA programs, projects, and missions, often concerned with subjects having substantial public interest.

- TECHNICAL TRANSLATION. Englishlanguage translations of foreign scientific and technical material pertinent to NASA's mission.

Specialized services also include creating custom thesauri, building customized databases, organizing and publishing research results.

For more information about the NASA STI program, see the following:

- Access the NASA STI program home page at http://www.sti.nasa.gov

- E-mail your question via the Internet to help@sti.nasa.gov

- Fax your question to the NASA STI Help Desk at 301-621-0134

- Telephone the NASA STI Help Desk at 301-621-0390

- Write to: NASA Center for AeroSpace Information (CASI) 7115 Standard Drive Hanover, MD 21076-1320 
NASA/TM-2007-214907

AIAA-2007-1198

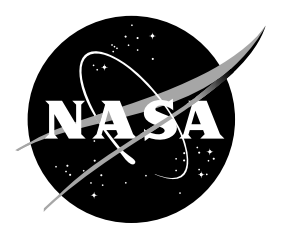

\section{Radio Frequency Mass Gauging of Propellants}

Gregory A. Zimmerli and Karl R. Vaden

Glenn Research Center, Cleveland, Ohio

Michael D. Herlacher

Analex Corporation, Brook Park, Ohio

David A. Buchanan and Neil T. Van Dresar

Glenn Research Center, Cleveland, Ohio

Prepared for the

45th AIAA Aerospace Sciences Meeting and Exhibit

sponsored by the American Institute of Aeronautics and Astronautics

Reno, Nevada, January 8-11, 2007

National Aeronautics and

Space Administration

Glenn Research Center

Cleveland, Ohio 44135 


\section{Acknowledgments}

This work was supported by NASA’s Propulsion and Cryogenic Advanced Development Project.

Trade names and trademarks are used in this report for identification only. Their usage does not constitute an official endorsement, either expressed or implied, by the National Aeronautics and Space Administration.

Level of Review: This material has been technically reviewed by technical management.

Available from

NASA Center for Aerospace Information 7115 Standard Drive

Hanover, MD 21076-1320
National Technical Information Service 5285 Port Royal Road Springfield, VA 22161 


\title{
Radio Frequency Mass Gauging of Propellants
}

\author{
Gregory A. Zimmerli and Karl R. Vaden \\ National Aeronautics and Space Administration \\ Glenn Research Center \\ Cleveland, Ohio 44135 \\ Michael D. Herlacher \\ Analex Corporation \\ Brook Park, Ohio 44142 \\ David A. Buchanan and Neil T. Van Dresar \\ National Aeronautics and Space Administration \\ Glenn Research Center \\ Cleveland, Ohio 44135
}

\begin{abstract}
A combined experimental and computer simulation effort was conducted to measure radio frequency (RF) tank resonance modes in a dewar partially filled with liquid oxygen, and compare the measurements with numerical simulations. The goal of the effort was to demonstrate that computer simulations of a tank's electromagnetic eigenmodes can be used to accurately predict ground-based measurements, thereby providing a computational tool for predicting tank modes in a low-gravity environment. Matching the measured resonant frequencies of several tank modes with computer simulations can be used to gauge the amount of liquid in a tank, thus providing a possible method to gauge cryogenic propellant tanks in low-gravity. Using a handheld RF spectrum analyzer and a small antenna in a 46 liter capacity dewar for experimental measurements, we have verified that the four lowest transverse magnetic eigenmodes can be accurately predicted as a function of liquid oxygen fill level using computer simulations. The input to the computer simulations consisted of tank dimensions, and the dielectric constant of the fluid. Without using any adjustable parameters, the calculated and measured frequencies agree such that the liquid oxygen fill level was gauged to within 2 percent full scale uncertainty. These results demonstrate the utility of using electromagnetic simulations to form the basis of an RF mass gauging technology with the power to simulate tank resonance frequencies from arbitrary fluid configurations.
\end{abstract}

\section{Nomenclature}

$\begin{array}{ll}c & \text { speed of light in vacuum } \\ f & \text { frequency } \\ L & \text { cylinder length } \\ R & \text { cylinder radius } \\ m, n, p & \text { indices of eigenmodes; integers } \\ \varepsilon & \text { dielectric constant } \\ Z & \text { impedance }\end{array}$

\section{Introduction}

The concept of measuring the electromagnetic eigenmodes of a tank as a method to gauge the quantity of liquid in a propellant tank dates back to 1966, when Lockheed Missiles and Space Company first tested the technique as a level sensor in tanks partially filled with RP-1, liquid hydrogen, and liquid oxygen (ref. 1). Since that time, several others have contributed to both the theoretical and experimental development of RF gauging, especially towards the development of using the technique as a method to gauge propellants tanks in low-gravity, where the configuration of the liquid in the tank is uncertain 
(refs. 2 to 5). Despite success with breadboard tests, the technique has not advanced to a high Technology Readiness Level, perhaps due in part to the complexity of signal analysis which includes the difficult task of converting a tank RF spectrum into a propellant quantity reading. The computing power available today makes this a much less daunting problem than in previous investigations. Moreover, the field modes of a tank can now be accurately predicted using commercial software packages, something that was not possible 20 years ago.

In simple tank geometries with a high degree of symmetry the electromagnetic eigenmodes can be calculated analytically. For example, a cylinder of length $L$ and radius $R$ will have transverse magnetic (TM) resonant frequencies at

$$
f=\frac{c}{2 \pi \sqrt{\varepsilon}} \sqrt{\frac{x_{m n}^{2}}{R^{2}}+\frac{p^{2} \pi^{2}}{L^{2}}}
$$

where $m=0,1,2, \ldots ; n=1,2,3, \ldots ; p=0,1,2, \ldots ; x_{m n}$ is the $n$th root of the Bessel equation $J_{m}(x)=0$, and $\varepsilon$ is the dielectric constant of the medium uniformly distributed in the cylinder (ref. 6). The lowest resonant frequency of a cylindrical tank corresponds to $(m, n, p)=(0,1,0)$ and is denoted as the TM010 mode. If the tank has a $1 \mathrm{~m}$ radius, the lowest TM mode is at $114.8 \mathrm{MHz}$ for an empty tank. Since typical tank sizes have resonant frequencies near the radio frequency spectrum, the technique is dubbed RF gauging. Filling a tank with liquid oxygen $(\varepsilon=1.488)$ or liquid hydrogen $(\varepsilon=1.23)$ would cause the resonant frequencies to decrease by 18 or 10 percent respectively from the empty tank value.

More complex tank geometries, such as a propellant tank with domed ends, internal tank hardware, and two-phase fluid distributions require computer simulations using finite element models which simultaneously solve Maxwell's equations in $10^{4}-10^{6}$ sub-volume elements. The accuracy of a computer simulation is likely limited by the fidelity of the tank and fluid model, numerical round-off errors, and available memory. Figure 1 shows a comparison of our measurements and simulations of RF resonances in an empty dewar. The simulations predict eigenmodes which are in good agreement with the measured resonances. Some of the eigenmodes predicted by the simulations (especially transverse electric modes) are not excited by the particular antenna geometry used in this measurement.

The goal of this work is to demonstrate that the first four TM eigenmodes measured in a small dewar can be accurately predicted at various liquid oxygen fill levels, thereby providing the basis for a lowgravity RF mass gauge technique. At a given fill level, the frequencies of the various modes will have some dependence on the fluid distribution in the tank. Thus, several modes would need to be analyzed

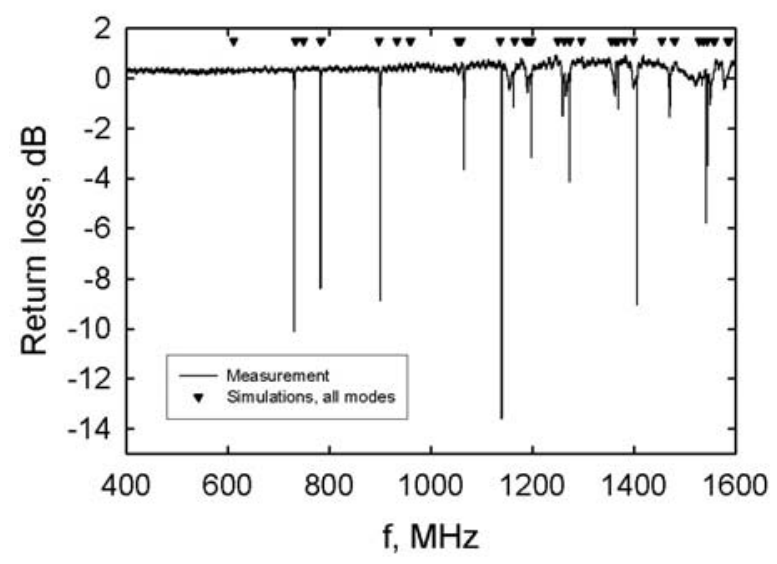

Figure 1.-Comparison of measured empty dewar RF resonance spectrum (solid line) with the first 50 eigenmodes calculated from numerical simulations (triangles). Not all of the eigenmodes were excited with the stub antenna, and several of the calculated eigenmodes are degenerate. 
and compared to simulations in order for the RF technique to work as a low-gravity mass gauge. In principle, such a gauge could function by comparing the measured frequencies of several modes to a database of simulations at various fill levels and liquid configurations. By finding the best match between the measured and simulated frequencies, the percent fill-level could be determined. Although the test results presented here are for only one liquid configuration (liquid settled on the bottom of the dewar), the results provide a sound basis for a more exhaustive study.

\section{Simulations}

CST's Microwave Studio (MWS) software was used to perform the numerical simulations (refs. 7 and 8). Microwave Studio is a commercial, general-purpose, electromagnetic simulator that contains three different electromagnetic solvers (transient solver, frequency domain solver, and eigenmode solver) that can be used for various high frequency applications. The eigenmode module calculates a finite number of modes in a closed structure by solving the Helmholtz equation for electromagnetic waves. The eigenmode module provides two solver methods: the Advanced Krylov Subspace (AKS) method and the JacobiDavidson (JD) method. The AKS method is faster and recommended for calculating many modes in a loss-free structure. The JD solver is the more robust solver and can handle lossy materials; however, the solver time is much longer. The AKS method was used to provide initial results in a short amount of time, and the JD solver was used for more extensive analysis. The solvers were found to be in excellent agreement with each other, with discrepancies in mode frequencies typically being less than 0.2 percent.

The 3-D structural model used in the simulations was based on measurements of the cylindrical dewar having an elliptical base. The total axial length of the inner volume of the dewar is $61 \mathrm{~cm}$, the radius is $15.7 \mathrm{~cm}$, and the depth of the elliptical base is $4.5 \mathrm{~cm}$. The empty dewar was modeled as a perfectly conducting electrical surface with an empty interior using 23,520 sub-volume elements. Figure 2 shows an example of the electric field vector amplitudes for the TM011 mode in the empty dewar. Liquid oxygen was characterized as an isotropic dielectric with a dielectric constant $\varepsilon=1.488$ (ref. 9). Different liquid oxygen fill levels were modeled by intersecting a block of liquid oxygen with the interior of the dewar. The height of the liquid oxygen block was varied as a percentage of total dewar length from 10 to 100 percent, in 10 percent increments. The volume of the resultant liquid oxygen object was calculated using post-processing routines.

Each simulation run consisted of calculating the lowest 50 eigenmodes for each of the liquid oxygen fill levels. For the empty dewar, the 50th eigenmode occurs at $1587 \mathrm{MHz}$. Several of the calculated eigenmodes are degenerate (two modes having the same resonant frequency for a different field configuration). Using a workstation running Windows XP 64-bit edition with two dual core processors and 4 GB of RAM, the total simulation time (11 runs) was less than $4 \mathrm{hr}$. Figure 3 shows the electric field amplitude contour plots of the four lowest TM modes as calculated by the simulations, for both an empty dewar and a $~ 50$ percent liquid oxygen fill level. The amplitudes of the field plots are normalized such that each mode contains a total energy of 1 Joule.

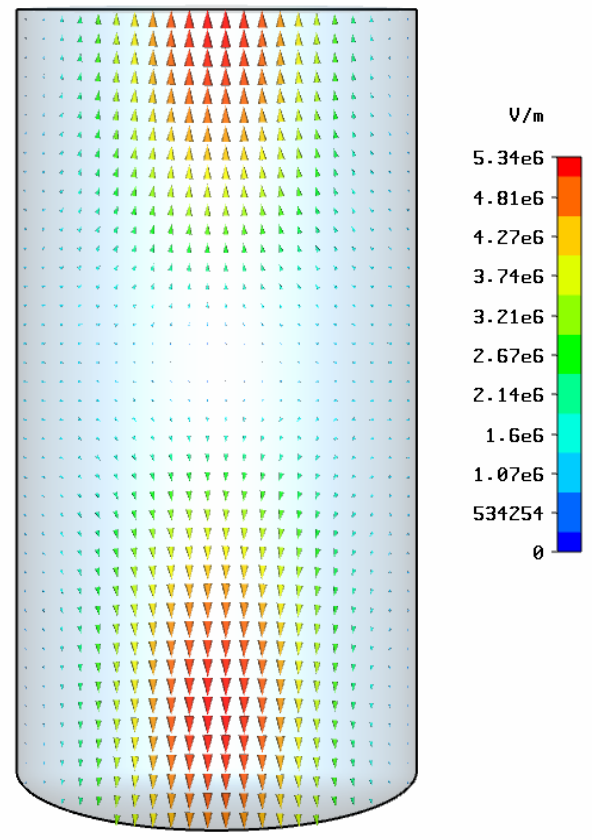

Figure 2.-Numerical simulations are used to calculate the electromagnetic eigenmodes of the dewar volume. Shown above is a plot of the electric field vector amplitude along the axial plane, computed for the empty tank TM011 mode. 

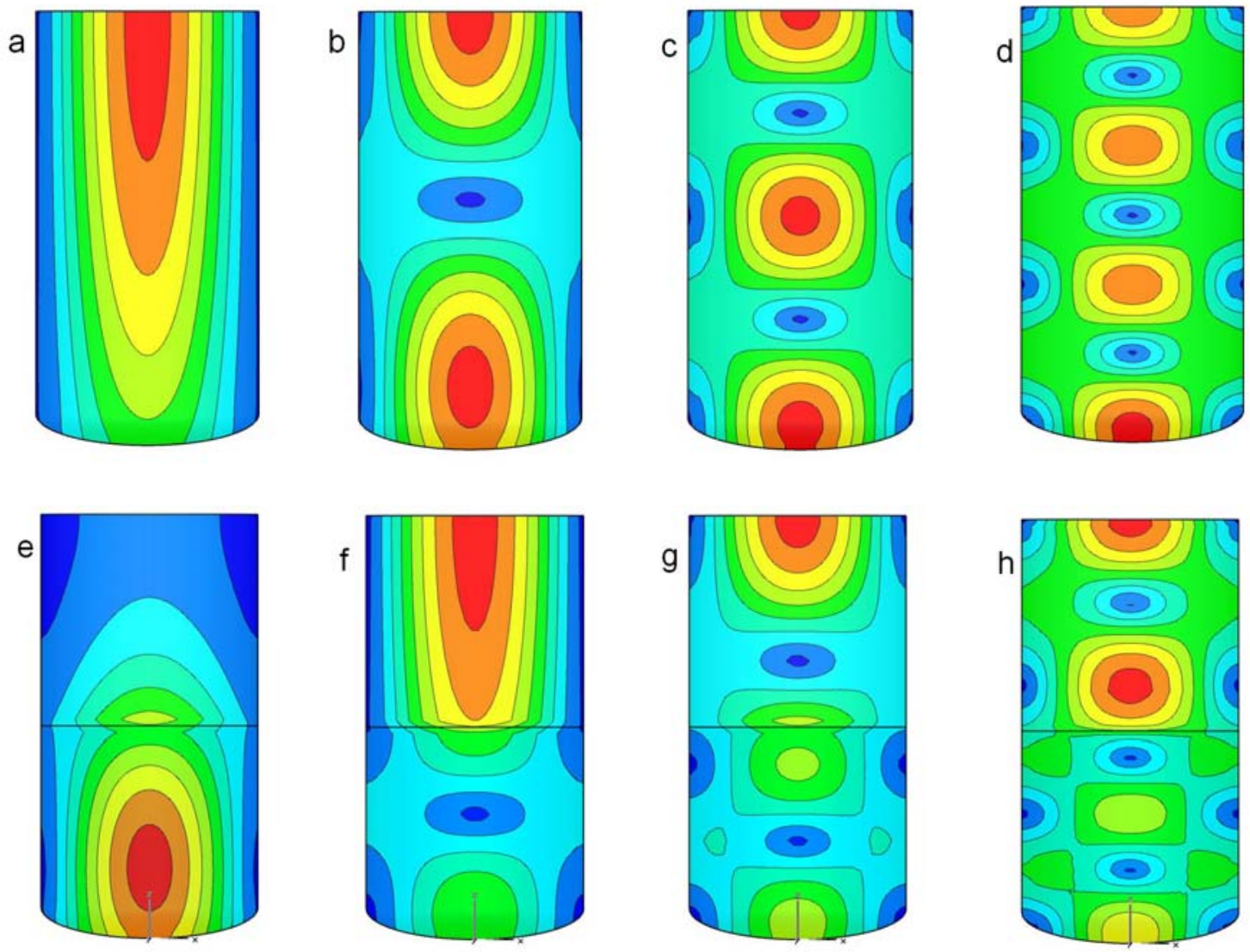

Figure 3.-Numerical simulations were used to generate these electric field amplitude contour plots of the four lowest TM modes [(a, e) - TM010; (b, f) - TM011; (c, g) - TM012; (d, h) -TM013] in the empty dewar (a-d) and at a 50 percent liquid oxygen fill level (e-h). High field regions are denoted in red.

\section{Measurements and Analysis}

A small dewar (46.1 liter capacity) was used as the test tank for the measurements. The dewar was placed on a calibrated floor scale, which provided the reference weighing system for determining the fill level (fig. 4). The percent fill level was determined by the ratio of the measured net weight of the liquid oxygen to the calculated full net weight, using $1.14 \mathrm{~g} / \mathrm{cc}$ as the density of liquid oxygen. The liquid oxygen fill tube, which extended to near the bottom of the dewar, was removed during the frequency scans. The vent holes in the dewar lid were covered on the underside of the lid using a fine metal mesh screen tack welded to the lid to contain the RF energy.

A straight $4 \mathrm{~cm}$ long antenna probe was mounted to the underside of the dewar lid, approximately $10 \mathrm{~cm}$ off the central axis, using a Type- $\mathrm{N}$ feedthrough. The antenna was fabricated by removing the outer conductor and dielectric spacer from a section of rigid copper coax, leaving the center conductor as the radiating element. No other internal hardware was inside the tank, thus providing an idealized test configuration.

The RF measurement apparatus consisted of a spectrum analyzer with built-in tracking generator, an $\mathrm{RF}$ bridge, and a $12 \mathrm{~m}$ long coax cable connecting the instrumentation to the antenna. A $0 \mathrm{dBm}$ source signal is output from the analyzer's tracking generator, through the RF bridge, to the antenna inside the tank. The power reflected from the antenna travels back through the coupled port on the RF bridge to the 


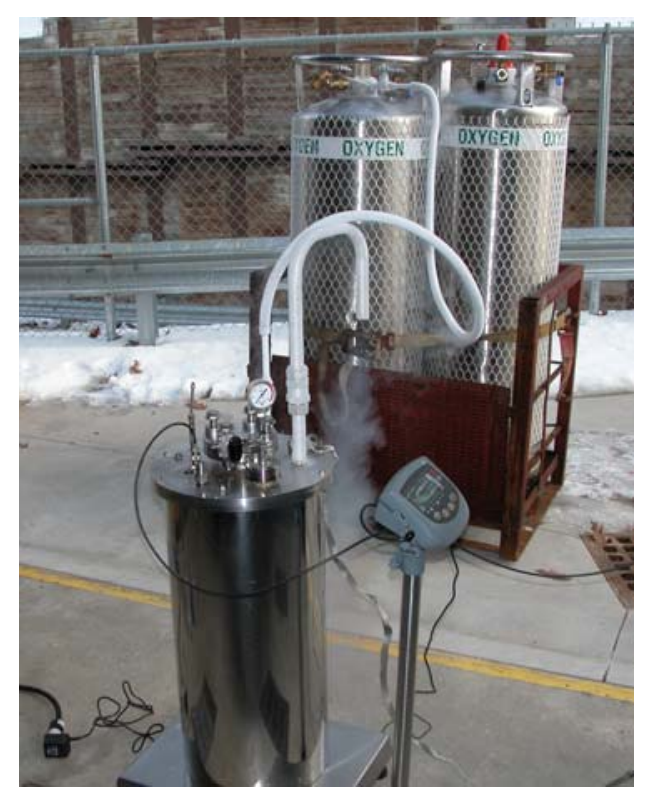
Figure 4.-The dewar was incrementally filled with liquid oxygen, and weighed using a floor scale to determine the fill level.

input of the analyzer. Prior to conducting measurements in the dewar, the RF measurement system was calibrated by successively attaching an electrical short, open, and $50 \Omega$ load to the end of the coax cable (in place of the antenna) and creating a set of vector reflection calibration files over a range of frequencies. The analyzer stores the calibration information, and uses the calibration files to determine the return loss when the antenna is connected to the measurement system. The vector calibration procedure minimized the amount of ripple on the calibrated $0 \mathrm{~dB}$ reference line, thus making it easier to find weak resonance signals. The return loss is a measure of the reflected power relative to the incident power, and is defined as

$$
\text { return } \operatorname{loss}(\mathrm{dB})=20 \log _{10}\left|\left(Z-Z_{0}\right) /\left(Z+Z_{0}\right)\right|
$$

where $Z$ is the impedance of the load and $Z_{0}$ is the impedance looking towards the source. When the antenna is excited at a frequency far from a tank resonant frequency, the power is completely reflected and the return loss is $0 \mathrm{~dB}$. At a resonant frequency, the RF energy may couple into the tank where it is dissipated in the tank walls, and the reflected power is low.

Figure 5 shows an example of the return loss spectrum from the tank at a liquid oxygen fill level of 38.1 percent. The resonant tank modes are clearly distinguished as sharp dips in the return loss. It is interesting to note that the TM010 mode $(648.9 \mathrm{MHz})$, which was clearly visible in the empty tank spectrum (fig. 1), is barely detected at this fill level. This is consistent with figure 3(e), which shows that the electric field configuration of the TM010 mode at a 50 percent fill level has a weak electric field component at the top of the tank where the antenna is located. As expected, the antenna poorly couples to the TM010 mode over a range of fill levels.

Return loss spectra were recorded at liquid oxygen fill levels of 0 percent (empty tank), 9.7, 19.1, 38.1, 57.6, and 76.8 percent. The frequencies of the lowest four measured modes as a function of fill level are compared with the simulations in figure 6 . The agreement between the simulations and measurements is excellent over the whole range of fill levels. As the tank fills with liquid oxygen, the frequencies of the various modes change in a complex, mode-dependent fashion. When the dielectric fluid intercepts the higher electric field regions of a mode, the frequency shift is larger. For example, the empty tank lowest 


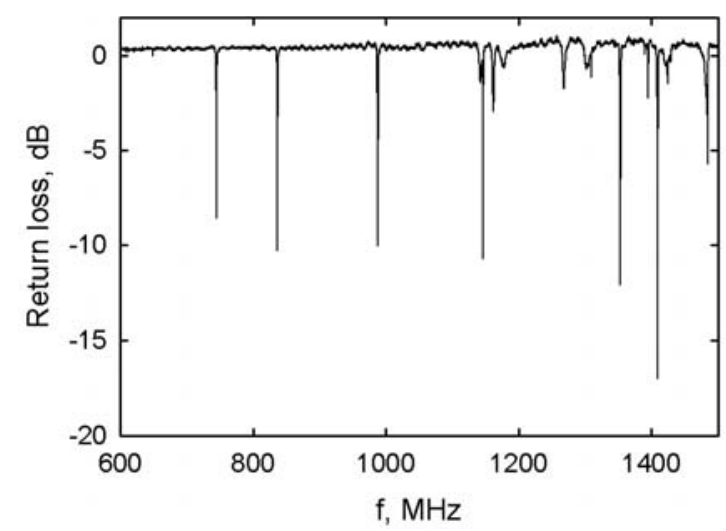

Figure 5.-Return loss spectrum of the dewar at 38.1 percent liquid oxygen fill level.

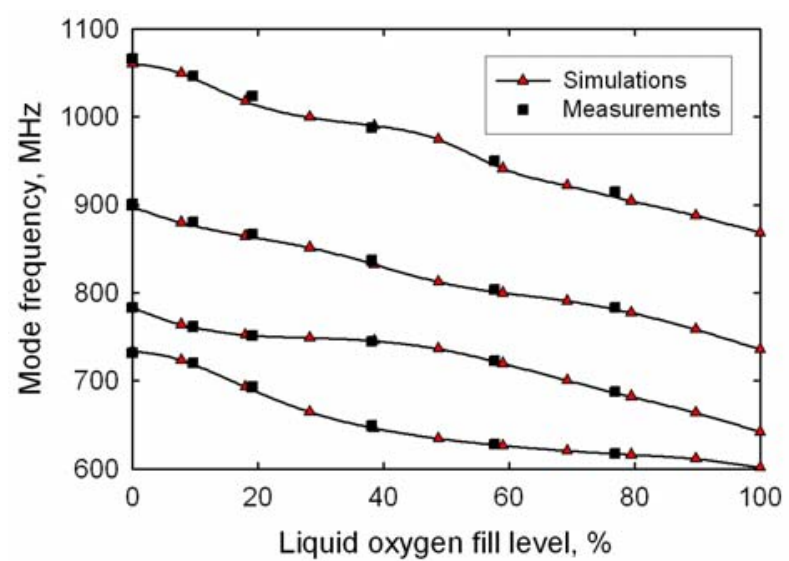

Figure 6.-Comparison of measured eigenmode frequencies (squares) with numerical simulations (triangles) as a function of liquid oxygen fill level. The solid lines are a smooth fit to the numerical simulation data. No adjustable parameters were used in the simulations.

mode has a relatively low-field region near the bottom of the tank (fig. 3(a)), so when the fluid begins to fill the tank, the frequency of that mode changes slowly at first. By the time the tank is half full of liquid oxygen, the electric field amplitude in the top half of the tank is relatively low (fig. 3(e)) so there is less frequency shift as the tank continues to fill. The TM011 mode (figs. 3(b) and (f)) displays the opposite trend. Higher order modes have regions of high electric field distributed more uniformly throughout the tank, and thus change in a more linear fashion as the tank is filled.

\section{Comments on Applying the Technique in Low-Gravity}

In low-gravity a possible fluid configuration is that in which the tank walls are completely wetted by the fluid, leaving a vapor pocket in the interior. The frequency response of the modes as a function of fill level would be different for a wetted wall liquid configuration, since the electric field amplitudes near the walls is relatively low. Because the modes are sensitive to the fluid distribution, in order to be effective as a low-gravity RF mass gauge several tank modes would have to be monitored and compared to numerical simulations. Using interpolated values of the numerically calculated eigenmode frequencies as the basis for a translation from the measured frequencies to a percent fill value, as might be done when used as a low-gravity RF mass gauge, we find that the RF gauge predicts the fill level to within 2 percent full scale uncertainty without using any adjustable parameters.

\section{References}

1. Lockhart, J. D., "RF Liquid Level Sensing Techniques” (Lockheed Missiles and Space), NASA CR74204, 1966.

2. Anon., "RF Quantity Gauging System” (Bendix Corp. report), NASA CR-115584, 1972.

3. Collier, R.S., Ellerbruch, D., Cruz, J.E., Stokes, R.W., Luft, P.E., Peterson, R.G., Heister, A.E., “Mass Quantity Gauging by RF Mode Analysis” (Interim report, National Bureau of Standards), N27390, 1973.

4. Bahr, A.J., Karp, A., "Study of Zero-g Propellant Gauging Based on Tank Electromagnetic Resonances” (Stanford Research Institute), NASA CR-150270, 1975. 
5. Anon., "Zero Gravity Quantity Gauging System Bench Top Tests,” (Ball Aerospace Report), ZG-011, May 1988.

6. Jackson, J.D., Classical Electrodynamics, 2nd ed., John-Wiley \& Sons, New York, 1975, Chap. 8.

7. In order to describe procedures adequately, it is occasionally necessary to identify commercial products by the manufacturer's name or label. In no instance does such identification imply endorsement by NASA, nor does it imply that the particular product is necessarily the best available for the purpose.

8. CST Studio Suite, Software Package, Ver. 2006.0.0, CST of America, Inc., Wellesley Hills, MA, 2006.

9. Celik, D., Van Sciver, S.W., "Dielectric Coefficient and Density of Subcooled Liquid Oxygen," Cryogenics, vol. 45, 356-361, 2005. 


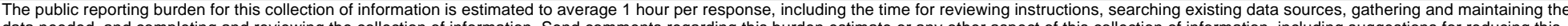

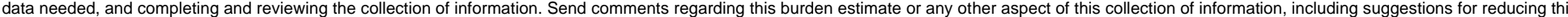

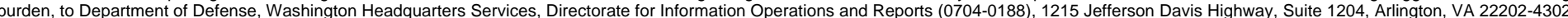

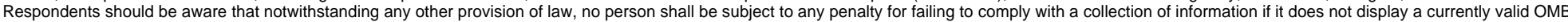
control number.

PLEASE DO NOT RETURN YOUR FORM TO THE ABOVE ADDRESS.

\section{REPORT DATE (DD-MM- $Y Y Y Y)$ \\ 2. REPORT TYPE \\ 3. DATES COVERED (From - To)}

01-08-2007

\section{TITLE AND SUBTITLE}

Radio Frequency Mass Gauging of Propellants

\section{5a. CONTRACT NUMBER}

5b. GRANT NUMBER

5c. PROGRAM ELEMENT NUMBER

\section{AUTHOR(S)}

Zimmerli, Gregory, A.; Vaden, Karl, R.; Herlacher, Michael, D.; Buchanan, David, A.; Van

Dresar, Neil, T.

\section{5d. PROJECT NUMBER}

5e. TASK NUMBER

5f. WORK UNIT NUMBER

WBS 253225.04.01.02.05.03.03

\section{PERFORMING ORGANIZATION NAME(S) AND ADDRESS(ES)}

National Aeronautics and Space Administration

\section{PERFORMING ORGANIZATION} REPORT NUMBER

John H. Glenn Research Center at Lewis Field E-16068

Cleveland, Ohio 44135-3191

\section{SPONSORING/MONITORING AGENCY NAME(S) AND ADDRESS(ES)}

National Aeronautics and Space Administration

Washington, DC 20546-0001

\section{SPONSORING/MONITORS ACRONYM(S) \\ NASA

11. SPONSORING/MONITORING
REPORT NUMBER
NASA/TM-2007-214907; AIAA-2007-
1198

\section{DISTRIBUTIONIAVAILABILITY STATEMENT}

Unclassified-Unlimited

Subject Category: 19

Available electronically at http://gltrs.grc.nasa.gov

This publication is available from the NASA Center for AeroSpace Information, 301-621-0390

\section{SUPPLEMENTARY NOTES}

\section{ABSTRACT}

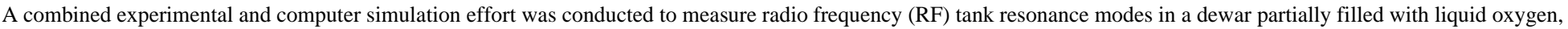

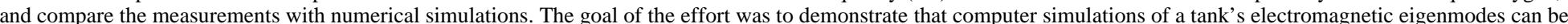

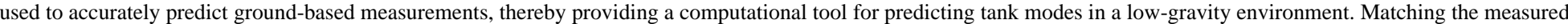

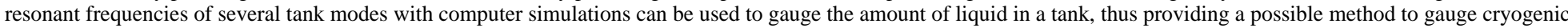

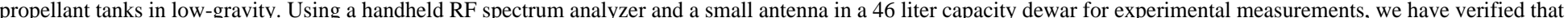

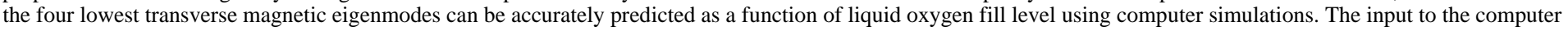

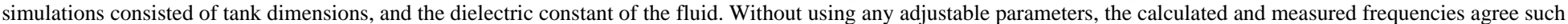

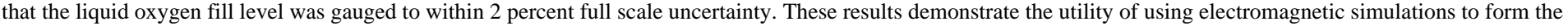
basis of an RF mass gauging technology with the power to simulate tank resonance frequencies from arbitrary fluid configurations.

\section{SUBJECT TERMS}

Fuel gages; Propellants; Radio frequencies; Microgravity

\begin{tabular}{|c|c|c|c|}
\hline \multicolumn{3}{|c|}{ 16. SECURITY CLASSIFICATION OF: } & \multirow{2}{*}{$\begin{array}{l}\text { 17. LIMITATION OF } \\
\text { ABSTRACT } \\
\text { UU }\end{array}$} \\
\hline $\begin{array}{l}\text { a. REPORT } \\
\text { U }\end{array}$ & $\begin{array}{l}\text { b. ABSTRACT } \\
\text { U }\end{array}$ & $\begin{array}{l}\text { c. THIS } \\
\text { PAGE } \\
\text { U }\end{array}$ & \\
\hline
\end{tabular}

18. NUMBER
OF
PAGES
13

\begin{tabular}{l} 
19a. NAME OF RESPONSIBLE PERSON \\
Gregory A. Zimmerli \\
\hline 19b. TELEPHONE NUMBER (include area code) \\
216-433-6577
\end{tabular}



